\title{
The Effect of Urban Geometry on Microclimate
}

\author{
Eleni Liapopoulou ${ }^{1}$, Yeonsook $\mathrm{Heo}^{2}$ \\ ${ }^{1}$ Department of Engineering, University of Cambridge, Cambridge, UK \\ ${ }^{2}$ School of Civil, Environmental and Architectural Engineering, Korea University, Seoul, Korea
}

\begin{abstract}
The aim of this paper is to investigate the effect of urban geometry on microclimate through a case study of the Greater London area. GIS data are used to describe the urban characteristics and calculate both spatial average and heterogeneity variables. Computational Fluid Dynamics (CFD) simulations are performed in areas of London in order to obtain their microclimatic conditions. The CFD simulations are performed using the standard k$\varepsilon$ turbulence model and Reynolds-Averaged Navier Stokes (RANS) equations. Next, correlation analyses using the Spearman's rank correlation coefficient are carried out to determine the impact of the urban variables on microclimate. The case study demonstrates that average urban density and building geometry have a substantial effect on microclimate. Furthermore, variation in building geometry and canyon ratio also have a significant impact. It is thus concluded that both average spatial variables and spatial heterogeneity should be included in urban climate studies.
\end{abstract}

\section{Introduction}

According to the 2014 Revision of World Urbanization Prospects, more than half (54\%) of the world's population lives in urban areas. In the last century, the world experienced the most intensive urbanization yet; and the coming decades are expected to attract even more people in cities, such that the world's population in 2050 is projected to be $66 \%$ urban, adding approximately another 2.5 billion dwellers (UN, 2014).

As cities grow bigger, so does the pressure placed on them to provide life quality for their inhabitants. Studying the built environment of cities is becoming more important, as they can have a significant effect on various sectors. "Managing urban areas has become one of the most important development challenges of the 21st century" said John Wilmoth, Director of UN DESA's Population Division (UN, 2014). Researching how this growing urbanization affects the microclimate of cities is attracting attention, since microclimatic conditions of cities are responsible for human well-being, outdoor thermal comfort, building energy performance, etc. The urban microclimate is influenced in a complex way by both natural and civic processes (Sharmin et al., 2017). Recent studies argue that microclimatic data are more important than meteorological weather data in regards to evaluating the performance of buildings in a city (Shahrestani et al.,
2015). This underlines the need to consider microclimatic information in urban planning.

Historically, urban microclimate studies were conducted with observational methods, such as field measurements, thermal remote sensing or small-scale modelling (e.g. wind-tunnel tests) (Toparlar et al., 2014). Lately however, with the advancement of computers, numerical approaches using Computational Fluid Dynamics (CFD) have been gaining popularity, since it is a fairly easy tool, requiring less time. A significant advantage of simulation approaches, compared to observational ones, is the possibility to try virtual scenarios and compare them. The main disadvantage however, is the necessity to make certain simplifications and assumptions in order to set up the physics of the model for study. Also, when possible, validation studies are useful in verifying the results (Toparlar et al., 2014). Toparlar et al., (2017) reviewed a total of 183 CFD studies on urban microclimate, which focused mainly on parameters related to temperature, wind flow, thermal comfort, heat transfer, and building energy consumption. All these studies confirm the relevance of urban climatology to engineers, architects, urban planners, financial analysts, and policy makers in order to compare urban design alternatives and to manifest guidelines.

This study investigates the relationship between urban variables and microclimatic data, focusing mainly on the urban heat island (UHI) effect. UHI is defined as a 'reverse oasis', where air and surface temperatures inside the city are hotter than in their rural surroundings (Gartland, 2012). It is mostly observed in air layers adjacent to the ground, in the so-called "canopy layer" of the town but is also present as a mesoscale phenomenon in the urban boundary layer. Research suggests that UHI can also be observed in the outskirts of a city, if the streets are narrow enough (Bärring et al., 1985). The most important causes of this phenomenon are the dense layout of cities, that obstructs air flow and ventilation, and the buildings' high thermal conductivity and heat capacity materials. This results in storing heat during the day and releasing it with a time delay at night, keeping air temperature constantly at high levels (Dimoudi et al., 2013). Also, urban building materials are generally watertight, hindering moisture from dissipating the sun's heat, and dark, trapping more solar radiation (Gartland, 2012). Moreover, increased anthropogenic heat production in cities contributes to the UHI intensity. London has a typical nocturnal UHI intensity of $3-4^{\circ} \mathrm{C}$, 
but it has also reached $9^{\circ} \mathrm{C}$ during warm summers (Oikonomou et al., 2012).

Studying how urban forms impact the UHI effect has been widely researched, and all studies agree that spatial variables should be taken into account during the design of urban layout (Bärring et al., 1985; Wong et al., 2011). Hu et al. (2016) conclude that the urban density of an area is a decisive parameter affecting the UHI intensity of that area. Simply by optimising the urban form layout, the UHI intensity can be reduced to $0.4-1^{\circ} \mathrm{C}$. However, these results are limited in the context of the particular study, which involved high-density areas in China. Another urban variable frequently studied is the building height. Research indicates that taller buildings result in an increase in the land surface temperature, and subsequently in the UHI intensity (Rezaei Rad et al., 2017). What is more, urban canyons, i.e. " the urban space defined by two adjacent buildings and the ground plane" have been identified as one of the key factors affecting the heat island effect and outdoor thermal comfort (Liao and Heo, 2018). Canyon ratio (building height / street width) affects the incoming and outgoing solar radiation, radiation flux, and wind flow in a site. Research suggests that deep canyons (high aspect ratio) perform well at day, decreasing solar gains and providing better outdoor thermal comfort. However, they trap long-wave radiation and release it later at night, causing a nocturnal heat-island effect (Elnahas, 2011; Sharmin et al., 2017). It is thus concluded that the impact of urban canyons on the microclimate can vary based on the time of the study, as well as on the specific climate characteristics of the study area.

This study aims to fill a knowledge gap in understanding how urban contexts influence the microclimate. There are numerous studies investigating the effect of average values of urban variables; however, few of them incorporate their variation. Recent research is calling for consideration of heterogeneity, rather than assuming homogeneous structures and layouts (Barlow, 2014). This study also addresses how changes in urban variables affect the microclimate. It has become increasingly important to study urban microclimatic environments and to apply these findings to improve outdoor thermal comfort and to mitigate the UHI effect.

\section{Methodology}

This paper investigates the effect of urban variables on microclimate, through a case study of the Greater London area. For this purpose, 8 urban variables are used, which adequately represent the urban morphology. The selected urban variables will be explained in detail later in this section. Except for the average variables, their standard deviation is also used to examine the effect of their spatial distribution. These variables are derived from GIS data of 40 appropriately chosen sites, with a plan area of 300x300 $\mathrm{m}$, located in the Greater London area. Next, CFD analyses are performed on these sites, using the software package PHOENICS and the standard k- $\varepsilon$ turbulence model. By having the same settings and input data for all the sites, it is assumed that any difference in the results is because of the difference in urban variables. The average air temperature and wind speed up to mean building height and their standard deviation are calculated for each site. Correlation analyses, using the Spearman rank coefficient, are later preformed between the urban variables and the data generated to assess their impact. Finally, conclusions are drawn on how appropriately selecting or modifying these variables can help mitigate the UHI effect.

\section{CFD Analysis}

CFD simulation is a useful tool gaining popularity, able to combine wind flow and heat transfer by conduction, convection, and radiation. This study uses the software "PHOENICS" (Parabolic Hyperbolic or Elliptic Numerical Integration Code Series), a general-purpose commercial CFD code. A comparative study among PHOENICS, Flow Design -a virtual wind tunnel tool developed by Autodesk-, and ODS studio -a platform developed to bring together many existing open-source tools- concluded that PHOENICS has the most difficult learning process but is the most efficient in accurately visualising regions far from the buildings. Comparing the 3 software with a mini airflow test, PHOENICS was found to have the most precise results (Sousa et al., 2015). Regarding the mathematical model of the CFD simulation, turbulence modelling is a key issue. For the prediction of turbulent flows, the Reynolds-Averaged Navier Stokes (RANS) equations are used. The RANS equations are derived by averaging the Navier-Stokes (NS) equations; time-averaging if the flow is statistically steady (steady RANS) or ensemble-averaging for transient flows (unsteady - URANS) (Blocken et al., 2016).

This study has used the standard k- $\varepsilon$ model, where $\mathrm{k}$ is the turbulent kinetic energy $\left(\mathrm{m}^{2} / \mathrm{s}^{2}\right)$, and $\varepsilon$ its dissipation rate $\left(\mathrm{m}^{2} / \mathrm{s}^{3}\right)$. It is a two-equation model, which gives a general description of turbulent properties of the flow by means of two transport equations. Turbulent fluid is treated as a laminar one with enlarged viscosity, then differential equations of turbulent motion are solved, from which the local values of enlarged viscosity are computed (CHAM, 2018). It is generally acknowledged that RANS CFD is deficient in reproducing turbulence intensities and gustiness that Large Eddy Simulation (LES) has the intrinsic ability to provide accurate estimates of (CHAM, 2018). RANS also suffers in accuracy in leeward regions; however it can be argued that these regions are less important for wind studies, as they have low amplification factors (CHAM, 2018). Nonetheless, the standard $k-\varepsilon$ model used is the most widely-used turbulence model for industrial applications and many studies have confirmed it is reasonably accurate.

The basic model settings for the CFD simulation are determined following the guidelines of the Architecture Institute of Japan (AIJ) (Tominaga et al., 2008). In order to adequately take into account the surrounding London morphology, the area of interest is nested in a bigger $600 \times 600 \mathrm{~m}$ surrounding area. The surroundings are modelled as a homogeneous grid of buildings, same for 
each site. The size of the 3-dimensional computational domain is $1500 \times 1500 \mathrm{~m}$, whereas the vertical boundary varies according to the maximum building height of each site. The grid is discretised in 12.7 million cells, which expand in size according to a specific factor as we move towards the domain end, and each simulation runs for 2000 iterations and $0.01 \%$ global convergence criterion. The simulation is set on a typical hot summer day with mild South-West wind, which is the prevailing wind direction in London. The wind velocity profile is logarithmic, and a fixed mass flow condition is applied at upwind domain faces, while a fixed pressure boundary is applied at downwind faces and at the sky. It is worth noting that the solar absorption coefficient is set rather low, at 0.1 to account for a fact that this is a steady simulation. The sun is modelled as shining on the objects for an infinite amount of time, so a lower absorption coefficient is needed to provide accurate results. The solar radiation (direct and diffuse) applies the heat load to objects within the domain, taking into account the latitude of the area, the time and date of the simulation, and the shading from surrounding objects. Thermal radiation is an important mode of heat transfer and is calculated as the radiative transfer between solids immersed in fluids which may or may not themselves emit and absorb radiation (CHAM, 2018). In more detail, the settings used in the model are presented in the following table:

\section{Table 1: CFD model settings}

\begin{tabular}{|c|c|c|}
\hline Base settings & \multicolumn{2}{|c|}{ Description } \\
\hline Domain Size & \multicolumn{2}{|c|}{$1500 \times 1500 \mathrm{~m}$} \\
\hline Total Number of Cells & \multicolumn{2}{|c|}{$\begin{array}{c}X=404, Y=404, Z=78 \\
12.7 \text { million }\end{array}$} \\
\hline Turbulence Model & \multicolumn{2}{|c|}{ Standard k- $\varepsilon$} \\
\hline Number of Iterations & \multicolumn{2}{|c|}{2000} \\
\hline $\begin{array}{c}\text { Global Convergence } \\
\text { Criterion }\end{array}$ & \multicolumn{2}{|c|}{$0.01 \%$} \\
\hline \multirow{2}{*}{$\begin{array}{c}\text { Inlet Boundary } \\
\text { Conditions (at reference } \\
\text { height of } 10 \mathrm{~m} \text { ) }\end{array}$} & Temperature & $26.3^{\circ} \mathrm{C}$ \\
\hline & Wind Speed & $3.2 \mathrm{~m} / \mathrm{s} \mathrm{SW}$ \\
\hline \multirow{2}{*}{ Solar Radiation } & Direct & $403 \mathrm{~W} / \mathrm{m}^{2}$ \\
\hline & Diffuse & $375 \mathrm{~W} / \mathrm{m}^{2}$ \\
\hline $\begin{array}{c}\text { Effective Terrain } \\
\text { Roughness Height }\end{array}$ & \multicolumn{2}{|c|}{$0.03 \mathrm{~m}$} \\
\hline $\begin{array}{l}\text { Coefficient for Wall } \\
\text { Functions }\end{array}$ & \multicolumn{2}{|c|}{ Logarithmic } \\
\hline \multirow{2}{*}{$\begin{array}{l}\text { Solar Absorption } \\
\text { Coefficient }\end{array}$} & Buildings & 0.1 \\
\hline & Ground & 0.1 \\
\hline \multirow{2}{*}{ Emissivity Coefficient } & Buildings & 0.92 \\
\hline & Ground & 0.88 \\
\hline Domain Material & \multicolumn{2}{|c|}{ Air using ideal Gas Law } \\
\hline density & \multicolumn{2}{|c|}{1.18} \\
\hline viscosity & \multicolumn{2}{|c|}{$1.83 \mathrm{E}-05$} \\
\hline specific heat & \multicolumn{2}{|c|}{1004} \\
\hline conductivity & \multicolumn{2}{|c|}{0.026} \\
\hline
\end{tabular}

The results of the CFD analysis of one site, in the form of air temperature are presented in the following figure.

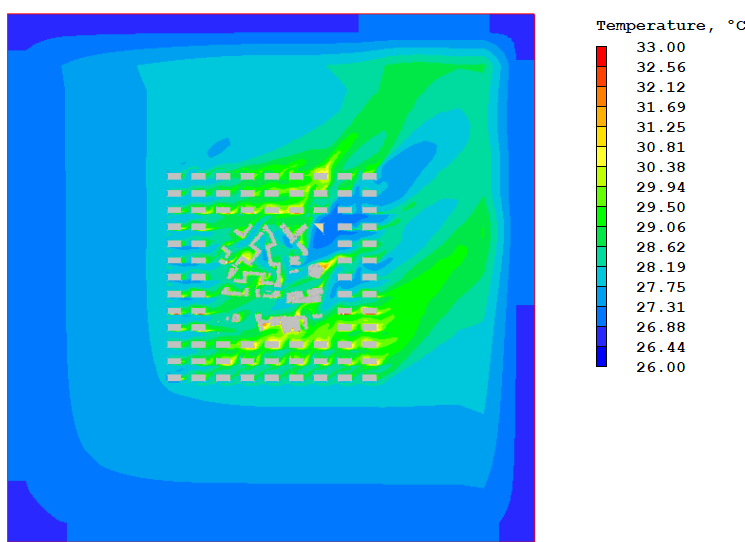

Figure 1: Air temperature results of one site

\section{Urban spatial variables}

\section{Average values}

The most commonly used variable in similar microclimate studies is the urban density. However, the literature review has shown that many other variables can have a significant impact. For this study, we use the some of the variables presented in (Liao and Heo, 2018). The variables are computed from GIS data in the format of shapefile provided by EDiNA Digimap that contains urban geometries for every city in UK (EDiNA 2018). The shapefile is read in ArcMap 10.5 and outputted into Python 2.7 for data processing and analysis. The 8 variables used, and their description are presented in Table 2:

Table 2: List of spatial variables

\begin{tabular}{|c|l|}
\hline Variable & \multicolumn{1}{|c|}{ Description } \\
\hline SC & $\begin{array}{l}\text { Site Coverage - total area of building footprints } \\
\text { in a site }\left(\mathrm{m}^{2}\right)\end{array}$ \\
\hline $\mathrm{NB}$ & Number of buildings in a site \\
\hline $\mathrm{ABH}$ & Average of building heights in a site $(\mathrm{m})$ \\
\hline $\mathrm{ABR}$ & $\begin{array}{l}\text { Average of building ratios (width/length) in a } \\
\text { site }\end{array}$ \\
\hline $\mathrm{ABF}$ & $\begin{array}{l}\text { Average of building footprint areas in a site } \\
\left(\mathrm{m}^{2}\right)\end{array}$ \\
\hline $\mathrm{ABS}$ & $\begin{array}{l}\text { Average of building surface (envelope) areas in } \\
\text { a site }\left(\mathrm{m}^{2}\right)\end{array}$ \\
\hline $\mathrm{PA}$ & $\begin{array}{l}\text { Pervious area, including green space and soil, } \\
\left.\text { in a site ( } \mathrm{m}^{2}\right)\end{array}$ \\
\hline $\mathrm{ACR}$ & $\begin{array}{l}\text { Average Canyon Ratio - average canyon street } \\
\text { height-to-canyon street width ratio }\end{array}$ \\
\hline
\end{tabular}

The variables are derived from GIS data by calculating the average value of all individual urban components in each selected $300 \mathrm{~m}-$ by- $300 \mathrm{~m}$ grid area. Site Coverage (SC) is a value commonly used to describe urban density and is calculated as the percentage of building footprint to the total site area. The number of buildings (NB) is also a very straight-forward variable in terms of its meaning, and it is usually associated with urban density. Average building height $(\mathrm{ABH})$ is calculated as the arithmetic mean of all the building heights in a site. Average building ratio 
$(\mathrm{ABR})$ is the arithmetic mean of all the building ratios in a site. When the building has a rectangular shape, the ratio is defined as width to length; when the shape is polygon, the ratio is defined as minimum to maximum distance between any two vertexes of the building footprint outline. Average Building Footprint (ABF) is the total area of all buildings' footprints on the horizontal plane. Average Building Surface (ABS) is the total sum of all building walls and roofs, assuming flat roofs for all the buildings. The shapefile provided by EDiNA has the following categories: "buildings", "roads, tracks and path", "structures", "land" and "water". Pervious area (PA) in a site is the sum of all areas falling in the "land" and "water" categories. Average Canyon Ratio (ACR) incorporates the street geometry and is calculated as the average building height to street width ratio (i.e. H/W) (Liao and Heo, 2018).

Table 3 summarises the statistical characteristics of the spatial variables for the 40 selected sites. The sites were selected so as to represent various urban forms and cover the extent of the possible values of the variables in the Greater London Area; hence the standard deviation is generally big. Mean site coverage is 0.39 , which is higher than the average site coverage for the entire London area $(0.17)$, because the majority of the sites selected were in central densely built areas. Nevertheless, the variation in number of buildings and building height is substantial. London generally has low building heights, with the mean value of the selected areas being $13.31 \mathrm{~m}$. The highest building selected was $33.31 \mathrm{~m}$ and it is found in a site in the City District of London. This is where the densest site of $\mathrm{SC}=0.67$ is also located. The least dense of the sites selected is found in a residential area in the south-east of London. Buildings are rather long-shaped, with an average building ratio of 0.39 . The sites with the least pervious areas are unsurprisingly located in the central area of London, whereas the site selected with the biggest pervious area is found south-west at Worcester Park. The sites were selected to assess the impact of urban forms, so large parks were generally avoided; this is the reason why the pervious area is relatively small (i.e. $33 \%$ of the site area). Canyons in the selected sites vary from deep to wide canyons; although the mean value of canyon ratio is close to $1(0.93)$. The widest street of the sites selected is located south-east at Orpington, while the narrowest and deepest canyon in the City District.

Table 3: Spatial variables of the selected sites

\begin{tabular}{|c|c|c|c|c|}
\hline Variable & Mean & Max. & Min. & Std Dev. \\
\hline $\mathrm{SC}$ & 0.39 & 0.67 & 0.13 & 0.14 \\
$\mathrm{NB}$ & 344 & 678 & 89 & 132 \\
$\mathrm{ABH}(\mathrm{m})$ & 13.31 & 33.31 & 5.04 & 6.00 \\
$\mathrm{ABR}$ & 0.39 & 0.54 & 0.33 & 0.06 \\
$\mathrm{ABF}\left(\mathrm{m}^{2}\right)$ & 139.29 & 510.67 & 34.13 & 104.61 \\
$\mathrm{ABS}\left(\mathrm{m}^{2}\right)$ & 289404 & 4784 & 208 & 881 \\
$\mathrm{PA}\left(\mathrm{km}^{2}\right)$ & 29285 & 64317 & 1867 & 16515 \\
$\mathrm{ACR}$ & 0.93 & 2.34 & 0.29 & 0.41 \\
\hline
\end{tabular}

Heterogeneity values

The previous variables demonstrate the average values of the variables of the selected areas. In order to represent spatial heterogeneity, it is important to know what the variation of these variables in a site is. There are two approaches of calculating the standard deviation of urban variables. For variables relating to building geometries (NB, ABH, ABR, ABF, ABS) the standard deviation is calculated by taking all building attributes across the site. For street and land use variables, the previously mentioned approach is not feasible, so we have to divide the area $(300 \times 300 \mathrm{~m})$ in a $3 \times 3$ grid. The average variables are calculated for each patch, and the standard deviation is derived from those 9 variables. However, as each patch is only $100 \times 100 \mathrm{~m}$ and there are variables which might extend to more than this distance, there potentially can be some inaccuracies in the standard deviation of these variables (Liao and Heo, 2018).

\section{Results}

This section examines the impact of average urban variables and their deviation on microclimatic conditions, and more specifically on air temperature and wind speed. In order to take into account variations along the vertical plane, the data studied are the average air temperature and wind speed of a volume covering the site up to the mean building height $(16.21 \mathrm{~m})$. By choosing this plane for all sites, we can study the microclimatic data in the urban canopy layer (UCL), which is the layer primarily influenced by the urban geometry, human activities and ground characteristics, and the area where UHI is mostly observed (Bakarman and Chang, 2016). Next, the microclimatic data acquired are correlated for each site against the urban variables. Correlation analyses using the Spearman rank coefficient are carried out between the urban variables and microclimatic results to assess their impact on the microclimate and specifically the UHI effect. The coefficient ranges from -1 to +1 , indicating strong negative and positive correlation respectively.

\section{Correlation between urban variables and wind speed}

This section examines the effect of urban variables on the average wind speed up to mean building height (16.21 m). Generally, the correlation coefficients in this section are higher than those between the urban variables and the air temperature, which indicates that in the studied model the urban variables have a more significant effect on the wind. Also, variables that are in positive correlation with wind speed are in negative with air temperature, since increased wind flow corresponds to heat removal. In other words, a variable that tends to cause high wind speed, will probably cause lower air temperatures and vice-versa. Figure 2 illustrates the correlation between wind speed and the spatial variables. Site coverage ( $\mathrm{SC}$ ) is strongly negatively correlated with wind velocity $(\mathrm{R}=-0.66)$, as it is suggested from the literature (Ok and Aygün, 1995), since dense areas full of buildings have few open spaces which do not allow the formation of substantial wind flow. Wind speed shows a strong negative correlation with building height, footprint, and surface. Tall and large buildings act as obstacles, slowing the wind flow due to sheltering effects. 
Wide-shaped buildings are moderately positively correlated with the wind speed. Pervious area (PA) has a strong impact both on the wind speed and air temperature, and in this case green areas tend to increase wind flow. Canyon ratio (H/W) has a significant negative correlation $(\mathrm{R}=-0.79)$ which indicates that deep canyons have lower wind speeds. A study by Memon et al., (2010) supports that deep canyons (high $\mathrm{H} / \mathrm{W}$ ratio) produce more vortices around buildings, and as the street width is closing in, the space left for free stream flow is further reduced.

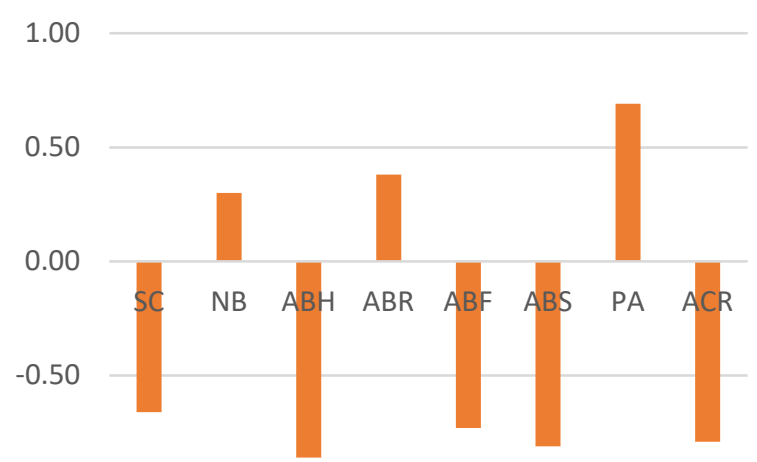

$-1.00$

Figure 2: Spearman's rank correlation coefficients between spatial variables and wind speed

Figure 3 shows the correlation between deviation of the spatial variables and the wind speed. Overall, the correlation coefficients of the deviations of the spatial variables are lower than those of the average spatial variables. Deviation in site coverage, building height, footprint and surface have the biggest impact, and tend to cause lower wind speeds. Although the average value of pervious area (PA) had a significant effect on wind velocity, its deviation has little influence. Non-uniform canyon ratios enhance wind speed $(\mathrm{R}=0.30)$ and decrease air temperature $(\mathrm{R}=-0.54)$ (shown in Figure 5). Sharmin, (2015) also suggested that non-uniform urban canyons can enhance urban ventilation.

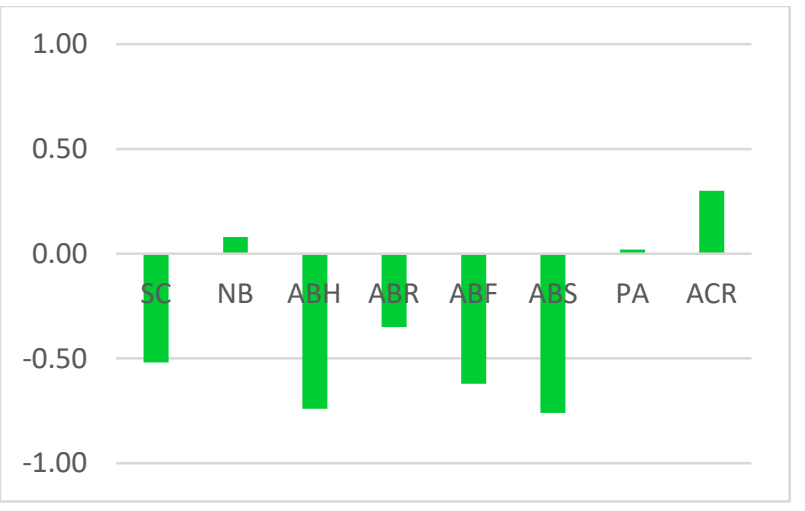

Figure 3: Spearman's rank correlation coefficients between standard deviation of spatial variables and wind speed

\section{Correlation between urban variables and air temperature}

Figure 4 illustrates the correlation between the average spatial variables and the air temperature. Dense areas are strongly correlated with the air temperature $(\mathrm{R}=0.76)$, since they do not allow the development of substantial airflow and they have less space for green areas, which can reduce the air temperature through evapotranspiration. Number of buildings (NB) has the strongest correlation $(\mathrm{R}=0.86)$. Building height is also strongly positively correlated $(\mathrm{R}=0.59)$. The solar radiation reaching inside the urban canyons is reflected back up at the walls of the buildings, which absorb the heat and release it back into the surrounding area. Tall buildings occupy more vertical space and thus are more likely to absorb and trap the solar radiation, resulting in increased temperatures (Bennet and Ewenz, 2013). Also, as seen from Figure 2, building height $(\mathrm{ABH})$ significantly decreases wind speed and, consequently, increases air temperature. Building variables, such as footprint $(\mathrm{ABF})$, and surface area (ABS), also substantially impact the air temperature for the same reason. Long-shaped buildings tend to cause higher temperatures in the area. As expected, pervious area (PA) has a strong impact on the air temperature $(\mathrm{R}=-0.73)$. Areas that have green and water areas have increased evapotranspiration, which removes the latent heat fluxes and decreases the air temperature. Also, trees' foliage provides shading and reduces the direct solar radiation under the tree canopy, significantly mitigating the heat stress (Ali-Toudert and Mayer, 2018). Deep canyons (high H/W ratio) are found to be positively correlated $(\mathrm{R}=0.66)$ with the air temperature. Some studies suggest that deep canyons are better in mitigating the UHI effect (Bakarman and Chang, 2016; Zakhour, 2015). However, as canyons are mostly associated with solar radiation and shading, the results can vary in different climatic and geographic conditions. In comparison to these studies performed in hot and humid climates, this study uses the temperate London climate.

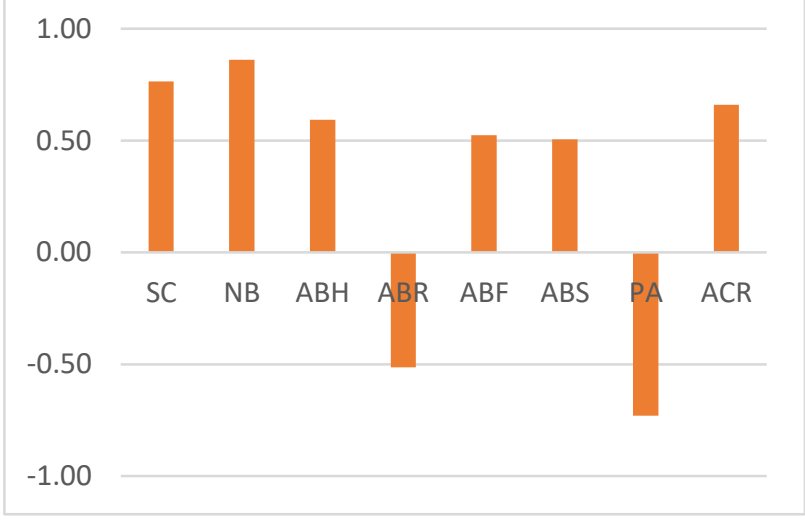

Figure 4: Spearman's rank correlation coefficients between spatial variables and $T_{\text {air }}$

Figure 5 presents the correlations between the standard deviations of the spatial variables and the average air temperature. Overall, the correlations coefficients are 
low. Although site coverage (SC) was one of the most important factors affecting the air temperature, its deviation has a small impact $(\mathrm{R}=0.14)$. Variation in building geometry (height, footprint, surface, ratio) has a moderate positive impact on the air temperature, but their impacts are less than the impact their average values have. Varying building ratio was found to have a small positive correlation, meaning that diverse building forms tend to cause higher temperature. Changes in pervious area (PA) have a slight negative correlation with the air temperature, even though its average value has a strong correlation coefficient. Variation in canyon ratio (ACR) has the biggest influence; diverse urban canyons are found to generate lower air temperatures than uniform ones (Sharmin et al., 2017).

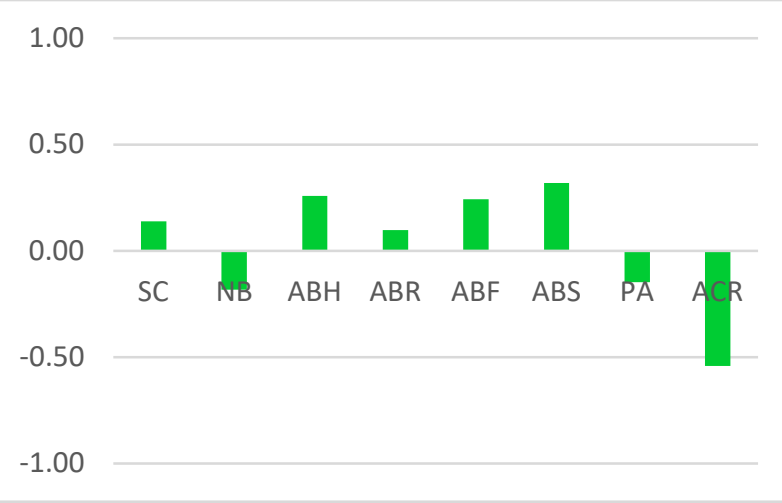

Figure 5: Spearman's rank correlation coefficients between standard deviation of spatial variables and $T_{\text {air }}$

\section{Conclusion}

This paper addresses the impact of urban variables on microclimate through a case study of London. 40 sites were selected in the Greater London area and CFD analyses were performed for each site. The average temperature and wind speed for each site were calculated, and they were correlated against urban variables using GIS data. Average values of these variables and their deviation in the selected areas were examined. Studying in detail how these variables affect the microclimatic environment can provide insights on how to properly modify them to improve urban microclimatic conditions and mitigate the UHI effect.

It was found that dense areas with strong SC are prone to developing the heat island effect. Compact areas exhibit higher air temperature due to heat stored in building materials and lower wind speed due to the higher roughness of the city compared to the rural surroundings, enhancing turbulence (Grawe et al., 2013). Smaller building volume in a site could help mitigate the UHI effect. Tall and large buildings tend to form UHI, as they increase the air temperature and decrease the wind speed. Varying building geometries, such as height, footprint, and surface area have a substantial effect on reducing wind flow. Green areas substantially mitigate the UHI effect. In the context of this study, deep canyons (high $\mathrm{H} / \mathrm{W}$ ratio) were found to cause lower wind speed and higher air temperature. Canyons with varying ratios substantially increase wind flow and heat removal. As a result, wide and non-uniform canyons are favoured. However, diversity in building geometries results in increased air temperature and UHI intensity.

Nevertheless, the trends found above are limited to the context of the studied area. Firstly, the correlation analyses are based on the results from 40 sites, which makes the statistical sample rather small. Also, calculating the standard deviation of some urban spatial variables may not accurately represent the actual variation. For example, deviation of street width could be imprecise, since it is calculated by dividing the area into 9 patches and obtaining the standard deviation of the average street width from these 9 patches only. In addition, many studies researching the UHI effect focus on air temperature at the pedestrian level (i.e. 1-2 $\mathrm{m}$ above the ground), whereas this paper studied the average air temperature up to the mean building height. Consequently, the results from this paper may not be directly comparable to the existing findings.

Overall, this study has proven that average spatial variables substantially affect microclimatic conditions. Their deviation in a site also shows an impact on microclimate, although it is generally lower than the average values. Hence, more research is needed to investigate the role of spatial heterogeneity in the microclimate for future urban climate studies. Therefore, this work and further studies can be of interest to engineers, designers, and urban planners, for the development of UHI mitigation strategies, as well as for understanding the degree to which the microclimate of cities is dependent on urban variables.

\section{Acknowledgement}

This work was supported by the scholarship of Foundation for Education and European Culture (IPEP). I would also like to thank PhD candidate Wei Liao for his important help throughout the study, especially with the GIS data.

\section{References}

Ali-Toudert, F., Mayer, H., 2018. EFFECTS OF STREET DESIGN ON OUTDOOR THERMAL COMFORT [WWW Document]. ResearchGate. URL

https://www.researchgate.net/publication/24215 7021_EFFECTS_OF_STREET_DESIGN_ON_ OUTDOOR_THERMAL_COMFORT

Bakarman, M.A., Chang, J.D., 2016. The Effect of Urban Geometry on the Microclimate in Hot- Arid Climates: A Case Study of Riyadh, Saudi Arabia [WWW Document]. ResearchGate. URL https://www.researchgate.net/publication/30644 8335_The_Effect_of_Urban_Geometry_on_the _Microclimate_in_Hot_Arid_Climates_A_Case _Study_of_Riyadh_Saudi_Arabia

Barlow, J.F., 2014. Progress in observing and modelling the urban boundary layer. Urban Clim., ICUC8: The 8th International Conference on Urban 
Climate and the 10th Symposium on the Urban Environment $10, \quad 216-240$. https://doi.org/10.1016/j.uclim.2014.03.011

Bärring, L., Mattsson, J.O., Lindqvist, S., 1985. Canyon geometry, street temperatures and urban heat island in malmö, sweden. J. Climatol. 5, 433444. https://doi.org/10.1002/joc.3370050410

Bennet, M.G., Ewenz, C.M., 2013. Increased Urban Heat Island Effect due to Building Height Increase 6.

Blocken, B., Stathopoulos, T., van Beeck, J.P.A.J., 2016. Pedestrian-level wind conditions around buildings: Review of wind-tunnel and CFD techniques and their accuracy for wind comfort assessment. Build. Environ. 100, 50-81. https://doi.org/10.1016/j.buildenv.2016.02.004

CHAM, 2018. TURBULENCE MODELS [WWW Document].

URL http://www.cham.co.uk/phoenics/d_polis/d_lecs /general/turb.htm

Dimoudi, A., Kantzioura, A., Zoras, S., Pallas, C., Kosmopoulos, P., 2013. Investigation of urban microclimate parameters in an urban center. Energy Build. 64, 1-9. https://doi.org/10.1016/j.enbuild.2013.04.014

EDiNA (2018). http://digimap.edina.ac.uk/

Elnahas, M.M., 2011. The Effects of Urban Configuration on Urban Air Temperatures. Archit. Sci. Rev. 46, 135-138. https://doi.org/10.1080/00038628.2003.969697 5

Gartland, L.M., 2012. Heat Islands : Understanding and Mitigating Heat in Urban Areas. Routledge. https://doi.org/10.4324/9781849771559

Grawe, D., Thompson, H.L., Salmond, J.A., Cai, X.-M., Schlünzen, K.H., 2013. Modelling the impact of urbanisation on regional climate in the Greater London Area. Int. J. Climatol. 33, 2388-2401. https://doi.org/10.1002/joc.3589

Hu, Y., White, M., Ding, W., 2016. An Urban Form Experiment on Urban Heat Island Effect in High Density Area. Procedia Eng., Fourth International Conference on Countermeasures to Urban Heat Island, 30-31 May and 1 June 2016 169 , $166-174$ https://doi.org/10.1016/j.proeng.2016.10.020

Liao, W. and Heo, Y., 2018. The Effect of Urban Spatial Characteristics on Microclimate. Building Simulation and Optimization Conference 2018

Memon, R.A., Leung, D.Y.C., Liu, C.-H., 2010. Effects of building aspect ratio and wind speed on air temperatures in urban-like street canyons. Build. Environ., International Symposium on the Interaction between Human and Building Environment Special Issue Section 45, 176-188. https://doi.org/10.1016/j.buildenv.2009.05.015

Oikonomou, E., Davies, M., Mavrogianni, A., Biddulph, P., Wilkinson, P., Kolokotroni, M., 2012. Modelling the relative importance of the urban heat island and the thermal quality of dwellings for overheating in London. Build. Environ. 57,
223-238.

https://doi.org/10.1016/j.buildenv.2012.04.002

Ok, D.V., Aygün, M., 1995. The Variations of Wind Speeds with Building Density in Urban Areas. Archit. Sci. Rev. 38, 87-95. https://doi.org/10.1080/00038628.1995.969678 3

Rezaei Rad, H., Rafieian, M., Sozer, H., 2017. Evaluating the effects of increasing of building height on land surface temperature. Int. J. Urban Manag. Energy Sustain. 1, 11-16. https://doi.org/10.22034/ijumes.2017.01.01.002

Shahrestani, M., Yao, R., Luo, Z., Turkbeyler, E., Davies, H., 2015. A field study of urban microclimates in London. Renew. Energy, Sustainable Development in Building and Environment (SuDBE) $2013 \quad$ 73, 3-9. https://doi.org/10.1016/j.renene.2014.05.061

Sharmin, T., Steemers, K., Matzarakis, A., 2017. Microclimatic modelling in assessing the impact of urban geometry on urban thermal environment. Sustain. Cities Soc. 34, 293-308. https://doi.org/10.1016/j.scs.2017.07.006

Sharmin, T., Steemers, K., Matzarakis, A., 2015. Analysis of microclimatic diversity and outdoor thermal comfort perceptions in the tropical megacity Dhaka, https://doi.org/10.1002/joc.4502

Sousa, J.P.M., Moya, R.A.C., Prohasky, D., Vaz, C.E.V., 2015. Empirical analysis of three wind simulation tools to support urban planning in early stages of design, in: Blucher Design Proceedings. Presented at the XIX Congresso da Sociedade Ibero-americana de Gráfica Digital 2015, pp. 363-370.

Tominaga, Y., Mochida, A., Yoshie, R., Kataoka, H., Nozu, T., Yoshikawa, M., Shirasawa, T., 2008. AIJ guidelines for practical applications of CFD to pedestrian wind environment around buildings. J. Wind Eng. Ind. Aerodyn., 4th International Symposium on Computational Wind Engineering (CWE2006) 96, 1749-1761. https://doi.org/10.1016/j.jweia.2008.02.058

Toparlar, Y., Blocken, B., Vos, P., van Heijst, G.J.F., Janssen, W.D., van Hooff, T., Montazeri, H., Timmermans, H.J.P., 2014. CFD simulation and validation of urban microclimate: A case study for Bergpolder Zuid, Rotterdam. Build. Environ., Special Issue: Climate adaptation in cities 83, 79-90. https://doi.org/10.1016/j.buildenv.2014.08.004

Toparlar, Y., Blocken, B., Maiheu, B., van Heijst, G.J.F., 2014. A review on the CFD analysis of urban microclimate. Renewable and Sustainable Energy Reviews 80, 1613-1640. https://doi.org/10.1016/j.rser.2017.05.248

UN, 2014. UN world urbanization prospects: The 2014 revision [WWW Document]. Eur. Environ. Agency. URL https://www.eea.europa.eu/data- 
and-maps/data/external/world-urbanizationprospects-the-2012-2

Wong, N.H., Jusuf, S.K., Syafii, N.I., Chen, Y., Hajadi, N., Sathyanarayanan, H., Manickavasagam, Y.V., 2011. Evaluation of the impact of the surrounding urban morphology on building energy consumption. Sol. Energy 85, 57-71. https://doi.org/10.1016/j.solener.2010.11.002

Zakhour, S., 2015. The impact of urban geometry on outdoor thermal comfort conditions in hot-arid region [WWW Document]. ResearchGate. URL https://www.researchgate.net/publication/32233 0055_The_impact_of_urban_geometry_on_out door_thermal_comfort_conditions_in_hotarid_region 